\title{
Effect of frameshift mutagen acriflavine on control of resistance genes in Acinetobacter baumannii
}

Correspondence

S. G. B. Amyes

s.g.b.amyes@ed.ac.uk

Received 24 August 2010

Accepted 15 October 2010

\author{
B. S. Lopes, A. Hamouda, J. Findlay and S. G. B. Amyes \\ Centre for Infectious Diseases, University of Edinburgh, Edinburgh, UK
}

\section{INTRODUCTION}

Acinetobacter baumannii is one of the most difficult noscocomial pathogens to treat, similar to other bacterial pathogens such as meticillin-resistant Staphylococcus aureus, Clostridium difficile and Pseudomonas aeruginosa. Hospitalacquired pneumonia is the most common infection caused by this organism (Peleg et al., 2008).

Nosocomial infections may be transmitted via aerosols, staff or even by inadequately disinfected medical devices (Spelman, 2002). Other common infections caused by this bacterium are ventilator-associated pneumonia, urinary tract infections and bacteraemia (Perez et al., 2007). It can also cause suppurative infections of the skin, and abdominal and central nervous system infections (Fournier \& Richet, 2006). The bacterium has developed

Abbreviation: OMP, outer-membrane protein. resistance to different types of $\beta$-lactam antibiotics by the production of $\beta$-lactamases, which include plasmidencoded class A (TEM/PER-1/VEB/SHV/CTX-M), class B (metallo- $\beta$-lactamases), class C (Acinetobacter derived cephalosporinases AmpC/bla $a_{\mathrm{ADC}}$ ) and class $\mathrm{D}$ (the oxacillinases: OXA-23-like, OXA-40-like, OXA-58-like and OXA-51-like, the latter being an intrinsic $\beta$-lactamase of A. baumannii) $\beta$-lactamases (Brown \& Amyes, 2006; Perez et al., 2007).

Outer membranes, like other biological membranes, are built as lipid bilayers that are permeable to hydrophobic molecules and are involved in the influx of nutrients and the efflux of toxic substrates or antibiotics which can hamper normal cell function (Nikaido, 2003). Three outermembrane proteins (OMPs) have been reported to be missing in the imipenem-resistant strains of A. baumannii: the first is a $33-36 \mathrm{kDa}$ protein, the second is a $29 \mathrm{kDa}$ protein designated $\mathrm{CarO}$ and the last is a $43 \mathrm{kDa}$ protein 
that shows significant peptide homology with OprD from P. aeruginosa (Vila et al., 2007).

Transposable elements are important in providing genetic variability and are generally tightly regulated (Mugnier et al., 2009). Insertion sequences are capable of independent transposition in the microbial genome and are also responsible for the spread of resistance and virulence determinants within the species (Mugnier et al., 2009). ISAba1 has been associated with the expression of several antibiotic resistance genes including $b l a_{\mathrm{OXA}-51-\text { like }}$ and $b l a_{\mathrm{ADC}}$ (Corvec et al., 2003, 2007). It is also known that frameshift products are involved in transposition of IS629, a member of the IS3 family (Chen \& Hu, 2006; Mahillon \& Chandler, 1998). ISAba1 belongs to the IS4 family, and it has been reported recently that it is capable of transposition and that the transposase gene is downregulated by translational frameshifting (Mugnier et al., 2009). It has also been reported that IS4Bsu1, a member of the IS4 family in Bacillus subtilis, is responsible for the genetic instability of poly- $\gamma$-glutamic acid production and that IS1999, a member of the same family, is responsible for expression of $\beta$-lactam resistance genes (Aubert et al., 2006; Nagai et al., 2000).

Acriflavine is known to cause frameshift mutations by intercalation in DNA (Kornberg, 1980). In this study, we evaluated the role of OMPs, other than the major OMPs, that might be involved in the transport of nutrients and influx of antibiotics, particularly imipenem, meropenem, ceftazidime and piperacillin/tazobactam, by comparing a parental strain, an acriflavine-resistant mutant and a strain serially subcultured on MacConkey agar. The role of acriflavine as a frameshift mutagen was evaluated with respect to its effect on the control of $b a_{\text {OXA-51-like }}$ and $b l a_{\mathrm{ADC}}$ as a result of the transposition of ISAbal. This study also aimed to identify the changes in levels of expression of antibiotic resistance genes due to the movement of ISAbal.

\section{METHODS}

The bacterial strains used this study were A. baumannii 153 (Ab153) (Nottingham, UK), A. baumannii 153 acriflavine mutant (Ab153M), A. baumannii 1225 (Ab1225) (Wroclaw, Poland), A. baumannii 1225 acriflavine mutant (Ab1225M) and A. baumannii 1225 serially subcultured strain (Ab1225s) (Wroclaw, Poland). All parental strains were kindly supplied by Dr K. J. Towner (Queens Medical Centre, Nottingham, UK).

Identification and typing. Isolates were screened for the conserved 16S-23S rRNA intergenic spacer sequence using primer 1 (5'-TTGTACACACCGCCCGTCA-3') and primer 2 (5'-GGTACTTAGATGTTTCAGTTC- $\left.3^{\prime}\right)$. The expected product size was $975 \mathrm{bp}$. Restriction of the product by the enzyme AluI produced fragments of 50, 125, 135, 165, 175 and 330 bp specific for A. baumannii. Restriction of the same product with NdeII produced fragments of 50, 110, 145, 330 and 360 bp specific for A. baumannii (Dolzani et al., 1995).

The strains were further identified as A. baumannii by amplification of the intrinsic $b l a_{\text {OXA-51-like }}$ gene by PCR with the primers oxa-69A (5'-CTAATAATTGATCTACTCAAG-3') and oxa-69B (5'-CCAGTGGATGGATAGATTATC- $\left.3^{\prime}\right)$ at an annealing temperature of $48{ }^{\circ} \mathrm{C}$.
The expected product sizes were $975 \mathrm{bp}$ for strains without ISAbal present upstream of the $b l a_{\text {OXA-51-like }}$ gene and $2155 \mathrm{bp}$ for strains with ISAbal present upstream of the bla $a_{\mathrm{OXA}-51-\text { like }}$ gene (Héritier et al., 2005).

The strains were screened for the $b l a_{\mathrm{ADC}}$ gene with primers ISADC1 (5'-GTTGCACTTGGTCGAATGAAAA-3') and ISADC2 (5'-ACGTCGCGAGTTGAAGTAAGTT- $3^{\prime}$ ) with an annealing temperature of $51{ }^{\circ} \mathrm{C}$. The expected product size was $751 \mathrm{bp}$ if ISAbal was located upstream of the $b l a_{\mathrm{ADC}}$ gene (Ruiz et al., 2007).

Mutational analysis and strain subculture. Strains Ab153 and Ab1225 were subjected to treatment with acriflavine after overnight growth in nutrient broth. Mutants were isolated using a gradient plate technique as described previously with a concentration range between 0.03 and $0.3 \%$ (Hunt \& Sandham, 1969). A single colony at the highest concentration was selected and tested for further analysis. Strain Ab1225s was serially subcultured daily on MacConkey agar for more than 150 days in order to check for OMP changes and the stability of ISAbal.

Antimicrobial susceptibility testing. The isolates were tested for their susceptibility to imipenem, meropenem, ceftazidime and piperacillin/tazobactam. MICs were determined by the agar doubledilution method according to British Society for Antimicrobial Chemotherapy (BSAC) methodology (Anonymous, 1991). The results were interpreted according to BSAC guidelines. The reference strains used for MIC testing were A. baumannii ATCC 19606, Escherichia coli NCTC 10418, P. aeruginosa NCTC 10662 and S. aureus NCTC 6571 (Andrews, 2007).

Analysis of gene expression. Expression of the $b l a_{\mathrm{OXA}-51-\text { like }}$ and $b l a_{\mathrm{ADC}}$ genes was analysed by RT-PCR. The primers used for $b l a_{\mathrm{ADC}}$ were ADC1 (5' ${ }^{\prime}$-CCGCGACAGCAGGTGGATA-3') and ADC2 (5'TCGGCTGATTTTCTTGGTT-3') with an annealing temperature of $51{ }^{\circ} \mathrm{C}$, producing a product of $451 \mathrm{bp}$ (Ruiz et al., 2007). The primers used for $b l a_{\text {OXA-51-like }}$ were 51F (5'-TTTCAGCCTGCTCACCTT-3') and 51R (5'-TTCCCTTGAGGCTGAACAAC-3') with an annealing temperature of $56{ }^{\circ} \mathrm{C}$, producing a product of $679 \mathrm{bp}$ (this study). Total RNA was extracted from isolates in the exponential growth phase using a RiboPure Bacteria kit (Ambion) and treated with the DNase I provided in the kit. cDNA was synthesized from $250 \mathrm{ng}$ RNA using an Access Quick RT-PCR System kit (Promega). PCR products were run on an agarose gel and stained with GelRed (Cambridge Bioscience) for visualization. PCR products were quantified using Quantity One Software version 4.6.1 (Bio-Rad). The 16S rRNA gene was amplified as an internal control using primers $16 \mathrm{~S}-\mathrm{F}$ ( $5^{\prime}$ GACGTACTCGCAGAATAAGC-3') and 16S-R (5'-TTAGTCTTGCGACCGTACTC-3') at an annealing temperature of $56{ }^{\circ} \mathrm{C}$ (Lin et al., 2009). The product size was $426 \mathrm{bp}$.

Analysis of OMP profiles. Strains were grown overnight in nutrient broth and OMP extraction was performed using a method described previously (Bossi \& Bossi-Figueroa, 2007). The protein profiles were studied by $10 \%$ SDS-PAGE with Molecular Weight Standards, Broad Range (New England Biolabs) used as a size marker. The protein concentration was estimated after reconstitution in buffer and approximately $45 \mu$ g protein was loaded into each well. After electrophoresis, the gels were stained with Coomassie Blue R-250 (Sigma).

\section{RESULTS}

\section{Identification and typing}

The isolates were screened for the conserved 16S-23S rRNA intergenic spacer sequences using primer 1 and 
primer 2 as described above, amplifying a product of 975 bp, specific to A baumannii.

A fragment of approximately $2155 \mathrm{bp}$ was obtained for strains Ab1225 and Ab1225s after amplification with the oxa-69A and oxa-69B primers, suggesting that the ISAba1 element was present upstream of the $b l a_{\text {OXA-51-like }}$ gene. If the ISAbal element was not present upstream, the fragment size was $975 \mathrm{bp}$, which was the size obtained for strain Ab153. ISAba1 was found upstream of the $b l a_{\mathrm{ADC}}$ gene in strains Ab1225 and Ab1225s, giving a product of $751 \mathrm{bp}$. To check for overexpression of the bla $a_{\text {OXA-51-like }}$ gene and transposition of the ISAbal element, mutational analysis was performed using the dye acriflavine as a frameshift mutagen.

Sequencing of the $b l a_{\mathrm{OXA}-51-\text { like }}$ gene revealed that $b l a_{\mathrm{OXA}-66}$ was present in strain $\mathrm{Ab} 153$ and $b l a_{\mathrm{OXA}-110}$ in strain Ab1225.

\section{Mutational analysis}

ISAba1 movement was recorded in Ab1225M and Ab153M after acriflavine treatment had been performed. It was observed that strain Ab1225M lost its ISAbal element, previously present upstream of the $b l a_{\mathrm{OXA}-51 \text {-like }}$ gene, giving a product size of $975 \mathrm{bp}$, whereas strain Ab153M gained the ISAbal element upstream of the $b l a_{\text {OXA-51-like }}$ gene with a product size of $2155 \mathrm{bp}$.

ISAba1 movement was seen upstream of the $b l a_{\mathrm{ADC}}$ gene in the acriflavine-treated Ab153M strain, but its loss was observed in the similarly treated strain Ab1225M. ISAba1 movement was not seen in the subcultured strain Ab1225s and its features remained identical with respect to the parental strain Ab1225. The ISAbal sequence of strains Ab153M, parental Ab1225 and Ab1225s did not show any mutations or nucleotide substitutions.

\section{Antimicrobial susceptibility testing}

Table 1 shows the changes in MICs in the A. baumannii parental, mutant and serially subcultured strains. An eightfold rise in MICs for imipenem was seen in Ab153M and an eightfold decrease was seen in Ab1225M with respect to the parental strains Ab153 and Ab1225. A fourfold and twofold decrease in MIC for imipenem and meropenem was seen in Ab1225s with respect to Ab1225. There was negligible difference seen in MIC values for ceftazidime. No major difference was seen in the MIC values of piperacillin/tazobactam except for a fourfold decrease observed in strain Ab1225s in comparison with the Ab1225 parental strain. As no ISAbal change was observed in Ab1225s, it was important to see whether there were any significant changes related to the OMPs of this strain, as it had a fourfold and twofold decrease in MIC for imipenem and meropenem compared with its parent, Ab1225.

\section{Analysis of gene expression}

Expression of the $b l a_{\mathrm{OXA}-51-l i k e}$ and $b l a_{\mathrm{ADC}}$ genes was analysed by RT-PCR and the products obtained were quantified using Quantity One software version 4.6.1. Product analysis determined that there was 2.7-fold increase in expression of the $b l a_{\mathrm{ADC}}$ gene for Ab153M compared with Ab153. There was a small decrease $(1.2$-fold $)$ seen in expression of the $b l a_{\mathrm{ADC}}$ gene for Ab1225M compared with Ab1225. A negligible difference was seen in expression of the $b l a_{\mathrm{ADC}}$ gene between Ab1225 and Ab1225s. It was observed that there was a 2.5-fold increase in expression of the $b l a_{\text {OXA-51-like }}$ gene in Ab153M compared with Ab153. There was a fivefold decrease in expression of bla $a_{\mathrm{OXA}-51-\text { like }}$ in Ab1225M compared with Ab1225, and a fourfold decrease in expression of bla OXA-51-like in Ab1225s compared with Ab1225. This was confirmed three times and the results recorded were based on the mean increase or decrease of individual strains.

\section{Analysis of OMP profiles}

Fig. 1 shows the OMP profiles obtained for the $A$. baumannii parental, mutant and serially subcultured strains. Analysis of the OMP profiles revealed significant differences between the Ab153 parental strain and Ab153M. There was reduced expression of the 17, 23 and $25 \mathrm{kDa}$ OMPs in the Ab153M strain with an increase in

Table 1. MICs of various antibiotics in the $A$. baumannii strains

\begin{tabular}{|c|c|c|c|c|c|c|}
\hline \multirow[t]{2}{*}{ Strain } & \multicolumn{4}{|c|}{$\operatorname{MIC}\left(\mathrm{mg} \mathrm{l}^{-1}\right)$} & \multirow{2}{*}{$\begin{array}{c}\text { Expression of } \\
b a_{\text {OXA-51-like }} \text { gene }^{\star}\end{array}$} & \multirow{2}{*}{$\begin{array}{l}\text { Expression of } \\
\text { bla }_{\mathrm{ADC}} \text { gene }^{\star}\end{array}$} \\
\hline & Imipenem & Meropenem & Piperacillin/tazobactam & Ceftazidime & & \\
\hline Ab153 & 0.25 & 1 & 32 & 32 & 0 & 0 \\
\hline Ab153M & 2 & 4 & 64 & 128 & +2.5 & +2.7 \\
\hline Ab1225 & 2 & 4 & 64 & 128 & 0 & 0 \\
\hline
\end{tabular}

${ }^{\star}$ Fold increase/decrease. 


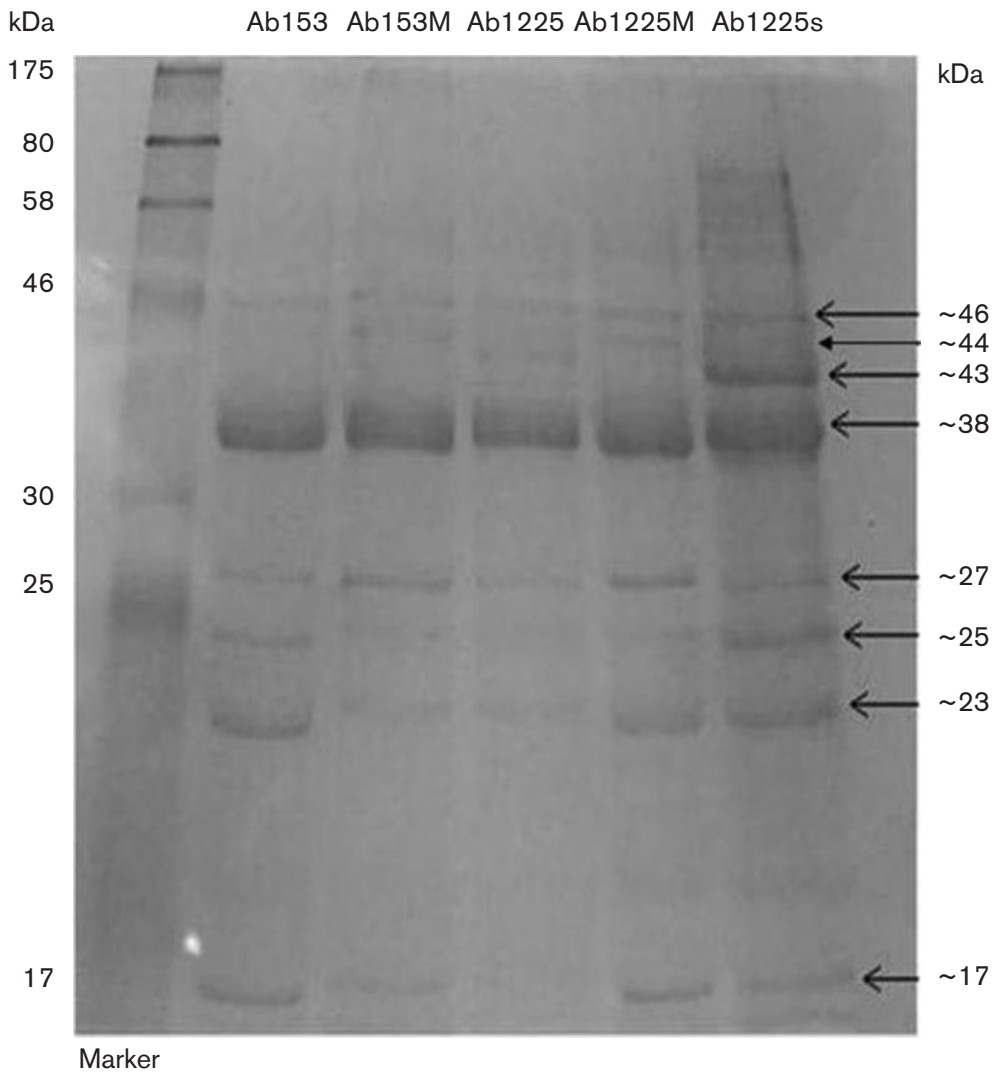

Fig. 1. OMP profiles of $A$. baumannii isolates. Ab153, parental strain; Ab153M, acriflavine mutant strain; Ab1225, parental strain; Ab1225M, acriflavine mutant strain; Ab1225s, MacConkey agar-subcultured strain.

MIC values. Ab1225M and Ab1225s exhibited an increase in expression of the 17, 23, 25 and $27 \mathrm{kDa}$ OMPs with a decrease in MICs, rendering the strain more susceptible to some antibiotics. The OMP pattern produced by Ab1225s showed significant overexpression of a $43 \mathrm{kDa}$ OMP.

\section{DISCUSSION}

All the A. baumannii strains were shown to exhibit different resistance profiles, which correlated with the movement of ISAbal upstream of the $b l a_{\mathrm{OXA}-51 \text {-like }}$ or $b l a_{\mathrm{ADC}}$ gene. The MIC values for the Ab153 and Ab1225 parental and mutant strains suggested that ISAbal may act as a promoter for the $b l a_{\mathrm{OXA}-51-\text { like }}$ or $b l a_{\mathrm{ADC}}$ gene. This is dependent upon ISAbal acting as a promoter rather than just being present upstream of the antibiotic resistance gene. This also addressed the fact that ISAbal may have a preferential role with respect to specific antibiotic resistance genes.

Strain Ab1225s had negligible effect on expression of the $b l a_{\mathrm{ADC}}$ gene with respect to its Ab1225 parent, both of which had ISAbal present upstream of the $b l a_{\mathrm{ADC}}$ gene. This is supported by the fact that resistance to oxyiminocephalosporins is mainly due to hyperproduction of AmpC-type $\beta$ lactamases (Rodríguez-Martínez et al., 2010). Ab1225s showed a fourfold decrease in $b l a_{\mathrm{OXA}-51-\text {-like }}$ gene expression concurring with MICs to the carbapenems. There was increased expression of the 17, 23, 25, 27 and $43 \mathrm{kDa}$ OMPs in Ab1225s, which led to a fourfold decrease in the MIC for imipenem, a twofold decrease in the MIC for meropenem and fourfold drop in the MIC for piperacillin/tazobactam. It was concluded that OMPs play a role in antibiotic resistance depending on the stress load of the compound and that they might be important for transport of the compound across the cell wall in either direction. The attenuation in Ab1225 may be due to OMP overexpression.

It was observed that all the A. baumannii isolates were resistant to ceftazidime, a fourth-generation cephalosporin, and thus ISAba1 may play a preferential role in increased expression of the $b l a_{\mathrm{OXA}-51-\text { like }}$ or $b l a_{\mathrm{ADC}}$ gene. This concurs with the fact that genetic organization of genes and their control play a crucial role in antibiotic resistance.

It was also observed that there was overexpression of OMPs in Ab1225M, which correlated with a decrease in MIC values for different antibiotics. Strains Ab153 and Ab153M had changes with respect to their OMP profiles. As an eightfold increase in resistance to imipenem and fourfold increase to meropenem was seen in $\mathrm{Ab} 153 \mathrm{M}$, it can be deduced that the resistance developed in Ab153M may be due not only to the movement of ISAbal upstream of the bla $a_{\mathrm{OXA}-51-\text { like }}$ gene but also to a contribution by the reduced expression of three OMPs corresponding to the 17,23 and $25 \mathrm{kDa}$ proteins, all of which were poorly expressed in the mutant strain.

In contrast, overexpression of the 17, 23, 25 and $27 \mathrm{kDa}$ OMPs could be seen in Ab1225M with a decrease in MIC 
values, suggesting that these proteins may have some implications with respect to the increased susceptibility in this strain, which had lost ISAbal upstream of the $b l a_{\mathrm{OXA}-51-\text { like }}$ and $b l a_{\mathrm{ADC}}$ genes. The MICs of ceftazidime and piperacillin/tazobactam in Ab153 and Ab1225 parent and mutant strains coupled with the changes in $\beta$-lactamase expression may indicate the contributions made by the individual enzymes to the level of resistance; for example, changes in expression of the $b l a_{\mathrm{ADC}}$ gene mirrored changes in the level of ceftazidime resistance.

It is clear from this study that the movement of ISAba1 is a strong factor for conferring resistance provided it is crucial for the gene action; if there is overexpression of primary surface structures of the bacterium, it can render the organism sensitive to a particular drug or poison.

Switching on the gene may be advantageous to this bacterium when it is required, as OMP changes can act synergistically; this was seen in Ab1225s and other strains and this depends on the action of promoters present for specific genes. This undoubtedly contributes to the organism's plasticity, making it resistant to different classes of antibiotics. Further studies to decipher the role of various factors involved in the pathogenesis of A. baumannii are necessary in order to understand its emergence as a multidrug-resistant pathogen.

\section{ACKNOWLEDGEMENTS}

We are grateful to the University of Edinburgh for the Overseas Research Scholarship and the College of Medicine and Veterinary Medicine bursary to B.S. L. We are grateful to the Medical Research Council for grant number RA0119, which funded part of this work.

\section{REFERENCES}

Andrews, J. M. (2007). BSAC standardized disc susceptibility testing method (version 6). J Antimicrob Chemother 60, 20-41.

Anonymous (1991). A guide to sensitivity testing. Report of the Working Party on Antibiotic Sensitivity Testing of the British Society for Antimicrobial Chemotherapy. J Antimicrob Chemother 27 (Suppl. D), 1-50.

Aubert, D., Naas, T., Héritier, C., Poirel, L. \& Nordmann, P. (2006). Functional characterization of IS 1999, an IS4 family element involved in mobilization and expression of $\beta$-lactam resistance genes. J Bacteriol 188, 6506-6514.

Bossi, L. \& Bossi-Figueroa, N. (2007). A small RNA downregulates LamB maltoprotein in Salmonella. Mol Microbiol 65, 799-810.

Brown, S. \& Amyes, S. G. B. (2006). OXA $\beta$-lactamases in Acinetobacter; the story so far. J Antimicrob Chemother 57, 1-3.

Chen, C.-C. \& Hu, S.-T. (2006). Two frameshift products involved in the transposition of bacterial insertion sequence IS629. J Biol Chem 281, 21617-21628.
Corvec, S., Caroff, N., Espaze, E., Giraudeau, C., Drugeon, H. \& Reynaud, A. (2003). AmpC cephalosporinase hyperproduction in Acinetobacter baumannii clinical strains. J Antimicrob Chemother 52, 629-635.

Corvec, S., Poirel, L., Naas, T., Drugeon, H. \& Nordmann, P. (2007). Genetics and expression of the carbapenem-hydrolyzing oxacillinase gene $b a_{\mathrm{OXA}-23}$ in Acinetobacter baumannii. Antimicrob Agents Chemother 51, 1530-1533.

Dolzani, L., Tonin, E., Lagatolla, C., Prandin, L. \& Monti-Bragadin, C. (1995). Identification of Acinetobacter isolates in the A. calcoaceticusA. baumannii complex by restriction analysis of the 16S-23S rRNA intergenic spacer sequences. J Clin Microbiol 33, 1108-1113.

Fournier, P. E. \& Richet, H. (2006). The epidemiology and control of Acinetobacter baumannii in health care facilities. Clin Infect Dis $\mathbf{4 2}$, 692-699.

Héritier, C., Poirel, L., Fournier, P.-E., Claverie, J.-M., Raoult, D. \& Nordmann, P. (2005). Characterization of the naturally occurring oxacillinase of Acinetobacter baumannii. Antimicrob Agents Chemother 49, 4174-4179.

Hunt, D. E. \& Sandham, H. J. (1969). Improved agar gradient-plate technique. Appl Microbiol 17, 329-330.

Kornberg, A. (1980). DNA Replication. San Francisco, USA: W. H. Freeman and Co.

Lin, L., Ling, B.-D. \& Li, X.-Z. (2009). Distribution of the multidrug efflux pump genes, adeABC, adeDE and adeIJK, and class 1 integron genes in multiple-antimicrobial-resistant clinical isolates of Acinetobacter baumannii-Acinetobacter calcoaceticus complex. Int $J$ Antimicrob Agents 33, 27-32.

Mahillon, J. \& Chandler, M. (1998). Insertion sequences. Microbiol Mol Biol Rev 62, 725-774.

Mugnier, P. D., Poirel, L. \& Nordmann, P. (2009). Functional analysis of insertion sequence ISAba1, responsible for genomic plasticity of Acinetobacter baumannii. J Bacteriol 191, 2414-2418.

Nagai, T., Phan Tran, L. S., Inatsu, Y. \& Itoh, Y. (2000). A new IS4 family insertion sequence, IS4Bsu1, responsible for genetic instability of poly- $\gamma$-glutamic acid production in Bacillus subtilis. J Bacteriol 182, 2387-2392.

Nikaido, H. (2003). Molecular basis of bacterial outer membrane permeability revisited. Microbiol Mol Biol Rev 67, 593-656.

Peleg, A. Y., Seifert, H. \& Paterson, D. L. (2008). Acinetobacter baumannii: emergence of a successful pathogen. Clin Microbiol Rev 21, 538-582.

Perez, F., Hujer, A. M., Hujer, K. M., Decker, B. K., Rather, P. N. \& Bonomo, R. A. (2007). Global challenge of multidrug-resistant Acinetobacter baumannii. Antimicrob Agents Chemother 51, 3471-3484.

Rodríguez-Martínez, J.-M., Nordmann, P., Ronco, E. \& Poirel, L. (2010). Extended-spectrum cephalosporinase in Acinetobacter baumannii. Antimicrob Agents Chemother 54, 3484-3488.

Ruiz, M., Marti, S., Fernandez-Cuenca, F., Alvaro, P. \& Vila, J. (2007). Prevalence of ISAbal in epidemiologically unrelated Acinetobacter baumannii clinical isolates. FEMS Microbiol Lett 274, 63-66.

Spelman, D. W. (2002). Hospital-acquired infections. Med J Aust 176, 286-291.

Vila, J., Martí, S. \& Sánchez-Céspedes, J. (2007). Porins, efflux pumps and multidrug resistance in Acinetobacter baumannii. J Antimicrob Chemother 59, 1210-1215. 